\title{
Niños, niñas y adolescentes migrantes venezolanos en Perú: atrapados entre dos marcos jurídicos de protección y de exclusión
}

\author{
Venezuelan children and adolescent migrants in Peru: caught \\ between two legal frameworks of protection and exclusion
}

\author{
Dánae Rivadeneyra Yriarte \\ Unité de Recherche Migrations et Sociétés - Université de Paris \\ derivadeneyra@gmail.com
}

Cómo citar/Citation: Dánae, Rivadeneyra. 2021. «Niños y niñas adolescentes migrantes venezolanos en Perú: atrapados entre dos marcos jurídicos de protección y de exclusión». Deusto Journal of Human Rights, No. 7: 65-94. doi: http://dx.doi.org/10.18543/djhr.2115.

Sumario: Introducción. 1. Terminología. 2. Principios protectores de los NNA migrantes: el marco jurídico internacional como garantía de cumplimiento de las políticas nacionales peruanas. 2.1. NNA migrantes, una doble protección jurídica. 2.2. NNA migrantes y el riesgo de una triple vulnerabilidad. 3. Entre la protección internacional y la soberanía nacional: los NNA migrantes venezolanos en Perú. 3.1. NNA en situación regular con padres en situación irregular. 3.1.1. Bascular hacia la irregularidad, el principal riesgo. 3.1.2. A más dispositivos migratorios cambiantes, más peligro de irregularidad. 3.2. NNA en situación irregular con padres en situación regular. Conclusiones. Bibliografía. Anexo

Resumen: El objetivo de este artículo es analizar cómo la política migratoria peruana, inscrita en una lógica de control de fronteras, se opone a los marcos normativos internacionales en cuanto a protección de los derechos humanos de los niños, niñas y adolescentes (NNA) migrantes venezolanos en Perú. Para ello y tomando como referencia la teoría de la justicia de Thomas Marshall, se analizan los marcos normativos nacionales e internacionales centrándose en la situación de estos NNA. A partir de los casos analizados se argumenta que la contradicción entre ambos marcos jurídicos conduce a una triple vulnerabilidad de estos NNA: por su condición de menores, de migrantes, y por verse envueltos en un dinamismo migratorio jurídico que los amenaza constantemente con bascular hacia la irregularidad. Se incluye aquí 
los casos emblemáticos recogidos en las ciudades de Lima y Tumbes en el tercer trimestre de 2019.

Palabras clave: migración venezolana; niños y adolescentes migrantes; política migratoria; derechos humanos, Perú.

Abstract: The aim of this article is to analyze how Peruvian migration policy, based on a logic of border control, goes against international normative frameworks in what regards the protection of Venezuelan children and adolescent migrants in Peru. To this end, and taking Thomas Marshall's theory of justice as a reference, local and international frameworks are analyzed, focusing on the situation of these children. The article argues that the contradiction between the two legal frameworks leads to a triple vulnerability of these children and adolescents: because of their status as minors, as migrants, and for being involved in a legal migratory dinamic that constantly threatens to drive them towards irregularity. The cases analyzed in this article were collected in Lima and Tumbes, in the third quarter of 2019.

Keywords: Venezuelan migration; children migrants; migration policy; human rights; Peru. 


\section{Introducción}

Actualmente, más de 1.043.460 venezolanos viven en Perú (ACNUR 2021, 149); y casi la mitad de ellos han solicitado asilo. Esto hace que Perú sea el segundo país de destino con el mayor número de personas de esta nacionalidad después de Colombia -hogar de más de 1,7 millones de venezolanos (ACNUR 2021, 99)- y, a nivel mundial, el primer país donde los venezolanos buscan asilo internacional. Esta situación es un nuevo desafío para el Perú porque, durante su pasado republicano, nunca recibió un flujo tan masivo de migrantes. Esto también revela un nuevo patrón migratorio «Sur-Sur» pues hasta 2010, la migración venezolana se dirigía hacia el norte, principalmente hacia Estados Unidos y España, correspondiendo a un patrón "Sur-Norte» (Koechlin, Vega y Solórzano 2018).

En este contexto, uno de los mayores desafíos de la migración venezolana tiene que ver con la situación de los niños, niñas y adolescentes (NNA) migrantes venezolanos en Perú. De manera aproximada, el $45 \%$ de venezolanos declaró estar a cargo de un NNA, "cuatro de cada diez tenían 5 años o menos, un tercio estaba en las edades entre 6 a 11 años, y los adolescentes fueron casi la cuarta parte» (Organización Internacional para las Migraciones. 2020a). En cuanto a la unidad familiar, el $27 \%$ de NNA tuvo que dejar a uno de sus padres en Venezuela, lo que aumenta el riesgo de ser víctima de violencia. ACNUR $(2021,148)$ señala también que al menos 344.000 NNA se encuentran en situación de vulnerabilidad y necesitan protección. Se calcula que más del $50 \%$ del total de NNA migrantes no está registrado en el sistema educativo y que solo 96.500 NNA migrantes venezolanos están escolarizados. En estas características se entrelazan diversos factores como pobreza, desprotección, informalidad, lo que permite tener una idea de su situación y de sus necesidades más apremiantes.

Este artículo ofrece una reflexión acerca del doble marco jurídico en el que se encuentran: uno de protección internacional por su condición de niños; y otro de exclusión, debido a políticas de seguridad nacionales, por su condición de migrantes. Analizaremos las raíces de esta contradicción a partir de la teoría de la justicia de Thomas Marshall (1997). En su ensayo, el sociólogo propone que los derechos fundamentales de una persona se encuentran íntimamente ligados al status de ciudadanía y encarnados en la figura del ciudadano, y ya no en el de la persona humana. A pesar de la antigüedad de la obra de Marshall, ésta recobra actualidad en el contexto sudamericano donde se evidencia esta oposición entre derechos internacionales y políticas 
de soberanía nacional, que se traduce en un privilegio de status del ciudadano sobre el migrante, convertido en «infraciudadano» (de Cabo y Pisarello 2017).

Dada la proximidad temporal de los sucesos documentados, se presenta un texto de tipo etnográfico con un marco jurídico de fondo, cuya finalidad no es ofrecer conclusiones finales ni establecer un análisis determinante, sino explorar las líneas de reflexión que se consideran importantes para empezar a tratar el tema de la niñez migrante en medio dos marcos jurídicos que en la práctica se oponen y exponen a estos NNA a una triple vulnerabilidad-debido a su minoría de edad, por su condición de migrantes, y por el riesgo constante de bascular hacia la irregularidad-. Partimos del análisis de que el reconocimiento que el nuevo Decreto Legislativo de migraciones del Perú de 2017 hace de los migrantes como titulares tanto de derechos como de garantías de estos (Acosta, Blouin y Freier 2019; Ceriani 2018) se ve limitado por una visión de excepcionalidad que condiciona un trato diferenciado en relación con los nacionales.

El enfoque de este documento es multidisciplinario pues combina el análisis de marcos jurídicos, y la aproximación sociológica desde un punto de vista comparativo. Para tal fin nos apoyaremos en los casos recibidos por la Clínica jurídica Pedro Arrupe (CJPA) del Servicio Jesuita de la Solidaridad en Lima. Los testimonios aquí recogidos forman parte de una serie de entrevistas semi-directivas realizadas en las oficinas de la CJPA entre setiembre y diciembre de 2019.

A partir de las consultas recibidas, la oficina dividió las consultas con NNA, en los siguientes grupos: NNA no acompañados en situación irregular, NNA en situación irregular con padres en situación regular, NNA en situación regular con padres en situación irregular y NNA en riesgo de apatridia. En este artículo no abordaré esta última categoría1.

Este documento se divide en tres partes. La primera analiza el marco jurídico internacional de protección de los derechos del niño en el que se enmarca la política nacional peruana. La segunda parte describe la oposición entre el marco jurídico de protección de la

1 El tema de la apatridia tiene un marco jurídico propio, así como un contexto regional específico que conviene desarrollar a profundidad en otro espacio. En 2019, el gobierno colombiano reconoció el derecho de suelo de niños de padres venezolanos nacidos en Colombia; sin embargo, ha sido estimado que al menos 24 mil niños se encuentran en esta condición. De estos, varios abandonaron el país y se encuentran hoy en Ecuador, Perú y Chile. 
niñez y el marco jurídico que gestiona las migraciones, lo que termina privilegiando el derecho de ciudadanía sobre los derechos humanos. Finalmente, en la tercera parte, a partir de los casos recogidos en la CJPA observaremos cómo esta oposición entre derechos y status de ciudadanos y migrantes impacta en los NNA con más fuerza que sobre otros grupos migrantes, convirtiéndolos en triplemente vulnerables. En esta última etapa del documento describiré también cómo el «dinamismo jurídico»², es decir, la multiplicación de leyes, prácticas y dispositivos migratorios implementado por el gobierno peruano, como respuesta a la migración venezolana, jugará un rol decisivo en la construcción de la triple vulnerabilidad de los NNA migrantes venezolanos. Esta estrategia peruana se alinea con la respuesta de otros países latinoamericanos frente a la emigración venezolana con el objetivo de desincentivarla (Acosta, Blouin y Freier 2019, 15).

\section{Terminología}

Utilizo la categoría pública de «migrante» para hacer referencia a los venezolanos que se encuentran en Perú. Esta decisión la tomo basada en el contexto actual el país, donde a nivel público, el uso de la categoría «inmigrante/migrante» empieza a asociarse a un estereotipo y a una posición de socialmente dominado mientras que la figura del extranjero está relacionada al ejecutivo o al científico que cuenta con un nivel de educación superior al promedio (Morice 2015). Poniendo así de manifiesto las relaciones desiguales y de poder que existen entre el país de acogida y el de origen, entre ambas sociedades y ambas culturas (Sayad 2006).

Dejo de lado, la categoría «inmigrante» pues para el caso peruano, limita a la persona a un recorrido puntual, de un punto de salida a un punto de llegada definitivo, de un Estado a otro. La experiencia ha demostrado que el proyecto migratorio de muchos venezolanos instalados en Perú no es un proyecto concluido sino en construcción y susceptible de modificarse de acuerdo a la situación del país que lo acoja (Acosta, Blouin y Freier 2019,4).

2 Término acuñado por mí para describir el aumento de decretos, resoluciones y prácticas migratorias para endurecer la política migratoria hacia los venezolanos. Ante esta situación muchos de ellos caen en la irregularidad. 


\section{Principios protectores de los NNA migrantes: el marco jurídico internacional como garantía de cumplimiento de las políticas nacionales peruanas}

Según la Convención de los Derechos del Niño, de la que Perú es parte firmante, se entiende por tal a todo menor de 18 años, más allá de las leyes sobre mayoría de edad de los Estados. Además, en el ámbito del Sistema Interamericano de Protección de Derechos Humanos (SIDH), tanto la CIDH (2008) como la Corte Interamericana (2002) han establecido que todas las personas menores de 18 años gozarán de los derechos establecidos para los niños.

Los Estados partes de la Convención de los Derechos del Niño están obligados a garantizar que todas las protecciones y estándares de la Convención aparezcan reflejados en la legislación nacional y deben considerar siempre los dos principios fundamentales de dicha Convención en la implementación de leyes, políticas o prácticas nacionales: el principio de no discriminación y el interés superior del niño (PICUM 2013). Se desprende de este último principio que, antes de tomar cualquier decisión que afecte a un niño, los Estados deben evaluar de forma exhaustiva su identidad, así como cualquier vulnerabilidad específica o necesidad de protección que pudiera tener, dando prioridad al interés superior del niño en todas las decisiones que afecten a la unidad familiar (Clínica Jurídica de los derechos de las personas migrantes y refugiadas 2020).

La legislación internacional también prevé un marco específico para que los NNA migrantes puedan acceder a una educación, salud y vivienda como derechos básicos (PICUM 2013), pues independientemente de su condición como regular o irregular sobre un territorio, se encuentran protegidos por todas las normas del marco internacional de derechos humanos ${ }^{3}$. Los aportes de la Corte Interamericana de Derechos Humanos han sido relevantes en este aspecto, siendo la Opinión Consultiva 21/2014 la que avanzó especialmente en los estándares para la protección internacional de la niñez pues aborda dos grandes grupos de niños migrantes: el de

3 Estas normas incluyen la Declaración Universal de Derechos Humanos y los cinco tratados fundamentales sobre derechos humanos: el Pacto Internacional de Derechos Civiles y Políticos, el Pacto Internacional de Derechos Económicos, Sociales y Culturales, la Convención contra la Tortura y otros Tratos o Penas Crueles, Inhumanos o Degradantes, la Convención Internacional sobre la Eliminación de todas las Formas de Discriminación Racial, y la Convención sobre la Eliminación de todas las Formas de Discriminación contra la Mujer. 
los que requieren protección internacional, refugiados y solicitantes de asilo, y el de los que llegan a un país por otras situaciones, con sus familias o solos, pero se encuentran vulnerables a posibles violaciones de derechos porque, por ejemplo, son víctimas de violencia o abuso familiar, trata de personas, trabajo infantil o, directamente, no acceden a la educación o a la salud porque sus padres no tienen la documentación adecuada, requiriendo así protección complementaria. El reconocimiento de este último grupo es de capital importancia pues es muchas veces la falta de acceso a derechos de los padres lo que termina colocando a estos NNA en situaciones de vulneración.

Sin embargo, es necesario mencionar que la interpretación de estos postulados, sobre todo lo que se refiere al interés superior del niño, así como sus alcances y aplicación para casos específicos permanecieron indefinidos por buen tiempo. Recién a principios del año 2000, el Comité de los Derechos del Niño (Organización de las Naciones Unidas 2005) publicó un instrumento donde se propone una interpretación de la Convención de Derecho del Niño y de su aplicación para los casos de niños «no acompañados» y/o «separados» que se encuentren fuera de su país de origen.

En el caso peruano, el Decreto Legislativo de Migraciones promulgado en 2017 significó un gran avance al incluir el enfoque de derechos humanos en su marco regulatorio. En la región, son varios los países que han incorporado tratados internacionales del derecho internacional de los derechos humanos en sus constituciones nacionales, promulgando leyes de migración con marcos legales específicos para la población refugiada (Blouin, Berganza y Freier 2018). Uno de los principios fundamentales de esta Ley de Migraciones es la unidad migratoria familiar, así como el interés superior del niño, en concordancia con los tratados internacionales de los que Perú es parte firmante.

La ley peruana reconoce la figura de las «niñas, niños y adolescentes extranjeros no acompañados», población considerada por la ley como «personas extranjeras en situación de vulnerabilidad» y en ese sentido, la Superintendencia Nacional de Migraciones ${ }^{4}$ (en adelante Migraciones) exhorta a las autoridades competentes a la adopción de medidas para la protección de sus derechos. Con el objetivo de darles un marco de protección jurídica, el Reglamento de la ley prevé para estos casos i) la calidad migratoria especial residente en atención a

4 Migraciones es un órgano del Estado Peruano, dependiente del Ministerio del Interior que se encarga del control migratorio interno y externo. 
su situación de extrema vulnerabilidad o ii) la calidad migratoria de residencia humanitaria, una calidad que protege a toda persona que no reúna los requisitos para la condición de asilado o refugiado y «se encuentre en situación de gran vulnerabilidad o peligro de vida en caso de abandono del territorio peruano» ${ }^{5}$.

El Estado peruano se compromete a garantizar el acceso a los servicios de salud pública "a la persona extranjera» "aun en situación migratoria irregular» ${ }^{6}$. También se garantizan los derechos de educación y acceso a la justicia.

En 2017, se aprobaron también los lineamientos para otorgar «el Permiso Temporal de Permanencia para las personas extranjeras madres o padres de hijos/as peruanos/as, así como los lineamientos para el otorgamiento del Permiso Temporal de Permanencia para las personas de nacionalidad venezolana» ${ }^{7}$. En el Plan Nacional de Derechos Humanos 2018-2021 se identificó a los NNA en «situación de movilidad», dentro de los «grupos de especial protección» y el Estado peruano se compromete a propiciar una protección integral de los NNA «no acompañados o separados extranjeros», a través de las calidades migratorias humanitaria y especial residente.

Si bien la legislación peruana se enmarca dentro de los acuerdos internacionales de los que es firmante, veremos posteriormente cómo su aplicación está sujeta a modificaciones normativas o a la actuación de las autoridades administrativas a cargo, yendo, muchas veces, en contra de la protección necesaria y reconocida en los instrumentos citados.

\subsection{NNA migrantes, una doble protección jurídica}

De manera general, los migrantes constituyen un grupo en situación de vulnerabilidad debido a situaciones de jure: desigualdades entre nacionales y extranjeros frente a las leyes; y de facto: desigualdades estructurales en la sociedad que se traducen en discursos absolutos, estigmatizando o achacando ciertas características culturales y que acaban materializándose en prácticas discriminatorias en función de la

5 Reglamento de la Ley art. 91 y art. 226.

6 Reglamento de la Ley art. 7.1

7 Decreto Supremo N. 001-2017-IN Lineamientos para el Otorgamiento del Permiso Temporal de Permanencia para las Personas Extranjeras Madres o Padres de Hijos/as Peruanos/as menores de edad e hijos/as mayores de edad con discapacidad permanente. 
nacionalidad del migrante. Esta situación conduce al establecimiento de diferencias en el acceso de unos y otros a los recursos públicos administrados por el Estado.

En el caso específico de los NNA migrantes, tanto las nomenclaturas utilizadas por el Comité de los Derechos del Niño que reconoce a niños «no acompañados» y/o "separados» que se encuentren fuera de su país de origen; como las categorías utilizadas por la Unión Europea que reconoce al "menor extranjero no acompañado» o el "separado»; así como la categoría utilizada por el Estado peruano que reconoce a los NNA extranjeros no acompañados; en esos tres ejemplos observamos que existen tres elementos que se encuentran siempre presentes y que describen la naturaleza de la categoría jurídica de estos NNA: minoría de edad, condición de no nacional y el peligro potencial ante la ausencia de padres o de representantes legales (Senovilla 2014).

La característica de minoría de edad implica una incapacidad jurídica o una capacidad muy limitada para defenderse en la sociedad. El niño posee derechos, pero es incapaz de ejercerlos por sí solo, necesita siempre de un adulto, de sus padres o tutores, que respondan por él y lo representen. La condición de niño está asociada a la necesidad de protección de un adulto, ya sea material, afectiva o moral.

La configuración de una persona como niña, niño o adolescente migrante implica entonces desde el punto de vista jurídico, una doble protección: primero por su condición de NNA y segundo por su condición de migrante.

\subsection{NNA migrantes y el riesgo de una triple vulnerabilidad}

Sin embargo, evidencia también una situación compleja cuando se trata desde las políticas nacionales y bajo la lógica de seguridad de fronteras. Por un lado, gracias a su condición de NNA, se les reconoce como personas que necesitan protección y asistencia por parte de sus representantes legales, en virtud de lo cual merecen una protección institucional; y, por otro lado, se les identifica también como personas extranjeras, como no nacionales, que pueden verse beneficiados de los servicios sociales del país de acogida y convertirse eventualmente en competencia en el mercado laboral frente a los nacionales.

Esta situación se torna aún más precaria cuando a la condición de niño y de migrante se suma la situación de irregularidad. Una situación que, en la práctica, se confunde con ilegalidad y conlleva al error de 
creer que estas personas entraron al país voluntariamente de manera irregular para vivir y mantenerse en esta situación, cuando lo que muchas veces sucede es que la mayoría entró al país de manera regular y debido a la expiración del documento, a la falta de información, de recursos o a la imposición de nuevos dispositivos, producto de políticas antimigrantes, no pudo regularizar nuevamente su situación. Así, al hablar de niños migrantes en situación de irregularidad, nos referimos a uno de los grupos humanos más vulnerables. De hecho, corren el riesgo de ser triplemente vulnerables: como niños, como migrantes y como potenciales personas en situación irregular.

En este contexto, la recepción de NNA migrantes se ha convertido en todo un desafío para los gobiernos que, en ciertos casos y pese a los compromisos internacionales adquiridos, han preferido una política de seguridad nacional frente a los NNA migrantes venezolanos. Un claro ejemplo es el caso colombiano donde, hasta 2019, el gobierno no reconocía el derecho de suelo sino solo el de sangre, lo que conllevó a que se niegue la nacionalidad colombiana a 24 mil niños de padres venezolanos nacidos en el territorio. En octubre de 2019 (Presidencia de Colombia, n.d.), el gobierno del país decidió reconocer como nacionales a estos niños, sin embargo, debido a las dinámicas migratorias, muchos de ellos ya habían abandonado el país rumbo a Ecuador, Perú o Chile, y son hoy apátridas o se encuentran en riesgo de serlo.

\section{Entre la protección internacional y la soberanía nacional: los NNA migrantes venezolanos en Perú}

Estos NNA se ven inmersos en dos ámbitos normativos: uno incluyente y otro excluyente. El primero, el de los derechos del niño, que por definición es garantista y protector de sus derechos humanos. El segundo, el de las normas de extranjería que en la práctica es muy restrictivo y no tiene un enfoque compatible con los derechos del niño. Las raíces de esta contradicción de ámbitos podemos encontrarlas en la teoría de la justicia de Thomas Marshall (1997), explicada en su ensayo Ciudadanía y Clase Social donde, según el sociólogo, los derechos fundamentales -civiles, sociales y políticos- se encuentran íntimamente ligados al status de ciudadanía y concentrados en la figura del ciudadano, y donde el garante del cumplimiento de estos derechos así como del status de ciudadano es el Estado; dejando así de lado cualquier vinculación con los derechos humanos. En un contexto mundial marcado por las llamadas "crisis migratorias», la obra de 
Marshall cobra especial importancia, sobre todo cuando se analizan las respuestas de los Estados frente a los movimientos migratorios. Sobre ello, Ferrajoli apunta que esta tesis:

está en contradicción con todas las constituciones modernas -no solo con la Declaración Universal de los Derechos de 1948, sino también con la mayor parte de las constituciones estatales que confieren casi todos estos derechos a las «personas» y no solo a los «ciudadanos»y ha sido lanzada en los últimos años, precisamente cuando nuestros acomodados países y nuestras ricas ciudadanías han comenzado a estar amenazadas por el fenómeno de las migraciones masivas (Ferrajoli 2001, 40-41).

El escenario descrito por Ferrajoli se evidencia en el caso peruano, a juzgar por el dinamismo jurídico en materia migratoria que ha experimentado el país en los últimos tres años y que ha implicado la aplicación de políticas, dispositivos y prácticas específicas de excepcionalidad, creadas en paralelo a los compromisos adquiridos internacionalmente. Como puede verse en el Anexo 1, el Estado peruano ha ido endureciendo su política migratoria hacia los venezolanos, a través de decretos o resoluciones, lo que brinda amplia discrecionalidad a las autoridades administrativas migratorias para decidir aún en contra de lo estipulado por el marco normativo nacional e internacional. Los cambios referidos, por ejemplo, al procedimiento de asilo en la frontera "no han sido comunicados jamás oficialmente» (Coordinadora Nacional de Derechos Humanos Perú 2020, 24). Así, la excepcionalidad se ha vuelto norma cuando se habla de poblaciones migrantes:

La actitud de los poderes públicos en relación con ellos, sobre todo si carecen de papeles, es la del auténtico señor del derecho al que nada le está vedado. Para gobernar sobre su vida y su muerte les basta con recurrir a las desigualdades que el ordenamiento jurídico establece entre ciudadanos y extranjeros, un verdadero apartheid interno que se suma al apartheid mundial creado a través de fronteras cada vez más inaccesibles (...) ser ciudadano comporta un privilegio de status que convierte a los inmigrantes que viven y trabajan en un sitio determinado en infraciudadanos o, directamente, en no personas (de Cabo y Pisarello 2017, 15-16).

La experiencia de trabajo de campo realizado en la Clínica Jurídica Pedro Arrupe (CJPA) del Servicio Jesuita al Migrante muestra precisamente la contradicción entre la teórica igualdad de derechos de 
estos NNA en tanto seres humanos y la excepcionalidad jurídica de la que hacen parte en tanto migrantes.

En los casos que observaremos a continuación veremos también cómo el dinamismo jurídico que evoqué líneas arriba es uno de los principales factores que fomenta la irregularidad. Esta se convierte así en el principal riesgo que persigue a los NNA y los amenaza con desaparecer en el sentido expresado por de Cabo y Pisarello (2017). Este bascular hacia la irregularidad se convierte en la tercera vulnerabilidad que se suma a las otras dos ya existentes por su condición de niños y migrantes.

Dentro de las múltiples situaciones en las que se ven envueltos los NNA migrantes venezolanos en Perú, hemos seleccionado dos categorías a partir de los casos recogidos:

— NNA en situación regular con padres en situación irregular.

— NNA en situación irregular con padres en situación regular.

La diferencia de los procesos migratorios entre 2017 y 2019 aquí descritos son representativos de decenas de otros casos recibidos en la Clínica Jurídica Pedro Arrupe. Mientras en 2016 y 2017 los venezolanos que llegaban a Perú pertenecían a la clase media de su país, habían realizado estudios superiores, y el proyecto migratorio había sido planificado con tiempo suficiente para activar los contactos en el país de destino y poder tener una estructura de acogida a su llegada, en 2019 la situación era completamente distinta, como lo muestra el caso siguiente.

\subsection{NNA en situación regular con padres en situación irregular}

Para explicar esta situación, analizaré el caso de Kiara Peña8, una menor de edad de nacionalidad venezolana que ingresó al Perú a los 16 años, junto a su bebé de tres meses, para reunirse con su pareja de 18 años que se encontraba ya en territorio peruano. Este es el caso de una niña separada a cargo de otro niño. Kiara llegó al Perú el 13 de agosto de 2019, cuando una de las primeras restricciones hacia los venezolanos, la obligatoriedad de la visa humanitaria, había entrado en vigor hacía dos meses 9 .

8 Nombre ficticio, elegido para proteger su identidad.

9 El 15 de junio del 2019, con el fin de restringir el acceso a su territorio, Perú anunció que las personas venezolanas necesitaban visa humanitaria para entrar en el país. Así quedó establecidó mediante la Resolución de la Superintendencia Nacional de Migraciones n. 000177-2019 del 12 de junio del 2019. 
Con esta medida, solamente los venezolanos con pasaporte -un factor excluyente debido al precio para adquirirlo (El Espectador 2020) ${ }^{10}$ - y aquellos que hubiesen tramitado sus antecedentes penales antes de entrar al Perú, podían entrar al país. Ambos requisitos para obtener la visa humanitaria constituían también factores excluyentes, pues el sueldo básico de muchos ciudadanos venezolanos no supera los 5 USD (Coordinadora Nacional de Derechos Humanos Perú 2020). Además, una de las características de la migración venezolana en 2019 es justamente la premura con la que se realiza el proyecto migratorio.

Días después de la promulgación del decreto de la visa humanitaria, el Estado peruano publicó otro decreto en el que se señalaban ciertas excepciones a esta disposición; entre ellas, una que incluía el caso de Kiara: «Menores de edad en tránsito hacia el Perú para reunirse con sus padres y que no cuenten con cédula de identidad o pasaporte sino únicamente con partida de nacimiento».

Tanto Kiara como su bebé entraban dentro de esta excepción ya que ambos niños no contaban con pasaporte sino solo con cédula de identidad venezolana y su objetivo de ingresar al Perú era reencontrarse con su núcleo familiar: el papá del bebé.

En la entrevista sostenida con la pareja, ellos explican que abandonaron su país debido a las condiciones de extrema pobreza que hacían peligrar la vida del bebé. Como en la mayoría de casos, la situación de los migrantes venezolanos de esta última etapa migratoria ${ }^{11}$ es bastante precaria. Las decisiones se toman de un día para otro y muchas veces sobre la ruta, lo que incrementa los riesgos, fragiliza aún más su situación y obviamente los deja al margen de los nuevos dispositivos migratorios como la obligatoriedad del pasaporte o el trámite previo de la visa humanitaria, imposibles de cumplir una vez llegados a la frontera.

10 A enero de 2020, el precio para tramitar un pasaporte colombiano era de aproximadamente 200 dólares.

11 De manera preliminar, tras las observaciones realizadas en 2019, dividí a los migrantes venezolanos en dos grupos: el primero compuesto por aquellos que ingresaron al Perú antes de las imposiciones de la visa humanitaria y restricciones; y el segundo por aquellos que entraron al Perú después de la imposición de la visa humanitaria. Cada grupo con un perfil socioeconómico diferente. Un reciente trabajo publicado por la Coordinadora Nacional de Derechos Humanos se orienta también en ese sentido, identificando a los migrantes venezolanos de la primera etapa como mayoritariamente hombres y con documento de identidad pasaporte, lo que, como vimos, es también un diferenciador de los recursos financieros de los que se dispone. 
El caso de esta pareja refleja el de muchas otras que entrevisté en Lima, por lo que es pertinente observar de cerca el recorrido antes, durante y después de haber llegado a Perú. La pareja de Kiara, Jeremy, decidió tentar suerte en Ecuador, en la ciudad de Machala, pero al llegar, su contacto, «un amigo con el que (Jeremy) había vendido cerveza» desapareció. Sin conocer a nadie y sin dinero, decidió continuar hasta Perú pues tenía un primo que ya se había instalado en el país. Tras 17 días de ruta a pie y haciendo autostop pudo llegar a Lima el 22 de mayo de 2019. Jeremy había atravesado Colombia de manera irregular, pues no llegó a tramitar la tarjeta de movilidad fronteriza, requisito entre los dos países, luego atravesó a pie Ecuador donde a pesar de no haber hecho control migratorio en Colombia sí le otorgaron su tarjeta andina, prueba de que había pasado los controles migratorios y de encontrarse en situación regular12. Con este documento llegó a la ciudad peruana de Tumbes, en la frontera con Ecuador, un mes antes de que entrara en vigencia la visa humanitaria peruana. Migraciones lo dejó entrar bajo la calidad migratoria de turista y autorizó su permanencia en el país por un período de 180 días.

Tres meses después y ya establecido en Perú, Jeremy pudo ahorrar un poco de dinero y se lo envió a Kiara para que se reuniera con él. A ella y a su bebé también las dejaron entrar bajo la calidad migratoria de turistas, como parte de las excepciones de la visa humanitaria, e igualmente autorizaron su estadía en territorio peruano por 180 días. Tras vivir varios meses en un albergue particular en el distrito de Villa El Salvador, hoy viven en un cuarto alquilado en el mismo distrito.

\subsubsection{BASCULAR HACIA LA IRREGULARIDAD, EL PRINCIPAL RIESGO}

En octubre de 2019, momento de la entrevista, la situación migratoria de esta familia era incierta. Si bien el permiso de permanencia de Kiara, como el de su bebé, se vencía en unos meses, Jeremy estaba a solo unas semanas de entrar en situación irregular porque no calificaba para tramitar ninguna calidad migratoria fuera del

12 Explico el recorrido de Jeremy pues evidencia el de muchos otros venezolanos, así como la forma de proceder de las autoridades migratorias colombianas, ecuatorianas y peruanas. Estos procedimientos habrían de cambiar pocos meses después también de manera coordinada haciendo imposible, por ejemplo, que una persona que atravesó irregularmente Ecuador pueda ser admitida en Perú, debido a la falta de sellos en su tarjeta migratoria. 
estatuto de refugiado. Solicitarlo representaba la última opción para esta familia.

En el contexto de la migración venezolana, decidir quién califica como refugiado ha sido una de las preguntas más complejas por responder, aún cuando existe un marco normativo que da una respuesta al respecto ${ }^{13}$. Perú es uno de los países firmantes de la Declaración de Cartagena que agrega a la definición clásica de refugiado de Ginebra de 1951 otras consideraciones que incluyen a las «personas que han huido de sus países porque su vida, seguridad o libertad han sido amenazadas por la violencia generalizada, la agresión extranjera, los conflictos internos, la violación masiva de los derechos humanos $u$ otras circunstancias que hayan perturbado gravemente el orden público» (Instrumentos Regionales sobre Refugiados y temas relacionados, s.f.).

Pese a lo que indica la Declaración de Cartagena, en la práctica son los lineamientos de la definición clásica de refugiado los que priman. Para obtener el estatuto de refugiado es necesario probar que se ha sido víctima de algún tipo de persecución política por parte del régimen del país de origen o que la amenaza la encarna algún grupo en específico. Los conflictos internos, la pobreza generalizada aún cuando amenazan gravemente la vida de las personas, no son considerados como un peligro al momento de estudiar el expediente de un solicitante de refugio ${ }^{14}$.

Sin embargo, es importante hacer una diferencia entre el estatuto de refugiado y la solicitud de refugio ${ }^{15}$. Actualmente, el solo hecho de solicitarlo abre la puerta a un trámite administrativo al que la Comisión Especial para los Refugiados (CEPR) deberá responder, y que permitirá a los solicitantes de refugio permanecer en el país de manera regular hasta que haya una respuesta a su petición, sea esta favorable o no.

En el caso peruano, entre 2014 y 2019 , solo se ha reconocido a 1.225 personas venezolanas y el $95 \%$ de dichos reconocimientos han sido bajo la definición tradicional de 1951. En el mismo plazo se han denegado 2.357 solicitudes (ACNUR 2020, 6). Hasta 2019, del total de solicitudes

13 Ley n. 27891, Ley del Refugiado promulgada el 20 de diciembre de 2002 y su reglamento Decreto Supremo n. 119-2003-RE.

14 En entrevista con uno de los responsables de la CEPR, esta persona me explicó que, si bien se rigen por la Convención de Ginebra, actúan «bajo el espíritu de Cartagena», lo que quiere decir que se hacen excepciones en función de los casos específicos. Así, aplicar la Convención de Cartagena es una excepción y no la norma.

15 Reglamento del Decreto Legislativo n. 1350, art. 4, inciso e. 
de refugio presentadas, aún estaban pendientes de respuesta 487.078 (ACNUR 2019, 74).

Gráfico 1

\section{Solicitudes de refugio presentadas por venezolanos en Perú 2010-2020}

300.000

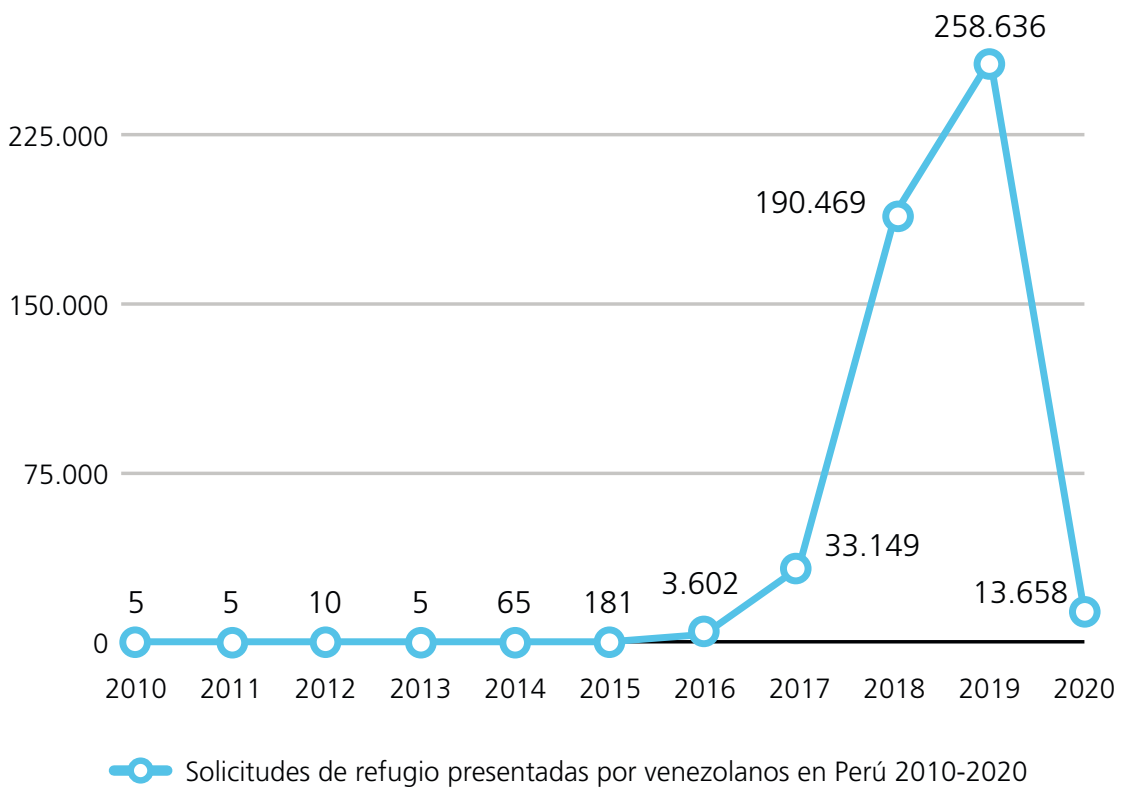

Fuente: Elaboración propia. Datos obtenidos a partir de las estadísticas sobre los refugiados de ACNUR https://www. unhcr.org/refugee-statistics/ download/?url=EZ|8|3. En este cuadro solo he incluido las peticiones hechas por la población venezolana. Para el año 2020, una posible explicación al descenso de solicitudes de refugio puede ser la crisis sanitaria de la Covid-19. El cierre de fronteras, además del confinamiento, fue una de las medidas principales para evitar el aumento de contagios.

De manera general, la crisis de Venezuela dio lugar a un fuerte aumento del número de solicitudes de asilo registradas en Perú en 2018 (192.500), que continuó en 2019 (259.800). Perú fue el segundo receptor más importante de solicitudes de asilo a nivel mundial en 2019, con casi todas las solicitudes presentadas por venezolanos. Estamos hablando de un incremento exponencial respecto a años anteriores, en los que se recibían, en promedio, 300 solicitudes por 
año. En octubre de 2019, frente a la afluencia de solicitudes, la plataforma de registro de la CEPR fue desactivada y por más de un mes su situación permaneció en suspenso. Luego se informó que las solicitudes se tramitarían únicamente de manera física ${ }^{16}$.

En el caso de Kiara Peña y su familia, solicitar el refugio representaba la última opción, pues si bien los autorizaba a quedarse en el país, el tiempo de demora del trámite desde la solicitud hasta obtener una respuesta definitiva -fuera esta negativa o positivaera indefinido. En la Clínica Jurídica Pedro Arrupe, se recibieron diariamente casos de solicitantes de refugio venezolanos cuya cita solo para recibir el carné de solicitante de refugio era para dentro de dos años, cuando el plazo estipulado por ley para determinar la condición de refugiado es de 60 días. El carné de solicitante de refugio es válido por un máximo de 60 días y renovable hasta que se obtenga una respuesta definitiva por parte de la CEPR. No representa ninguna calidad migratoria, aunque sí permite tramitar una autorización de trabajo por el tiempo de validez del carné, lo que es casi imposible en la práctica. El carné de solicitante de refugio es útil, sobre todo, durante los controles de identidad pues otorga legitimidad frente a los policías.

\subsubsection{A MÁS DISPOSITIVOS MIGRATORIOS CAMBIANTES, MÁS PELIGRO DE IRREGULARIDAD}

Una de las características del contexto actual en Perú es el dinamismo de las disposiciones migratorias y de los criterios con los que se aplican. Kiara y su bebé lo sufren en carne propia, pues a los meses de haber llegado a Perú y aún en situación regular, decidieron acercarse a la oficina de Migraciones y solicitar la calidad migratoria de residencia humanitaria. Según la Nueva ley de Migraciones, esta calidad migratoria está dirigida

Para el extranjero que encontrándose en territorio nacional y sin reunir los requisitos para acceder a la condición de asilado o refugiado, se encuentre en situación de gran vulnerabilidad o peligro de vida en caso de abandono del territorio peruano (...) Del mismo modo, será aplicable para los solicitantes de refugio y asilo o (...) o para las niñas, niños y adolescentes no acompañados; o para apátridas. También se aplica para personas que se encuentren

16 Durante el período de confinamiento debido a la crisis del nuevo coronavirus, la CEPR permaneció inactiva tanto de manera física como virtual. 
fuera del territorio nacional en situaciones excepcionales de crisis humanitaria reconocida internacionalmente, que soliciten venir al Perú y obtener protección.

Aunque no figura en el Reglamento, en la actualidad, la $\mathrm{CMH}$ solo puede ser obtenida si se tramita en los consulados peruanos de Venezuela, Colombia y Ecuador, bajo la forma de la Visa humanitaria. Una vez en el territorio se canjea por el carné de extranjería bajo la calidad humanitaria (ACNUR 2020).

La otra opción implementada para los NNA no acompañados es la calidad migratoria Especial Residente por extrema vulnerabilidad ${ }^{17}$. Pese a lo que manifiesta la ley Migraciones, la oficina encargada de tramitar y emitir estas calidades migratorias no aceptó la solicitud de Kiara ni la de su bebé pues, de acuerdo a los criterios actuales, solo se admiten a trámite los casos de enfermedades muy graves y que además tengan la característica de ser pobre o extremadamente pobre, previa evaluación socioeconómica realizada por el Sistema de Focalización de Hogares, dependiente del Ministerio de Desarrollo e Inclusión Social.

La condición de pobreza extrema sí es un criterio que Kiara y su núcleo familiar satisfacen, pero eso no es suficiente. En aquella época los tres vivían en un albergue en una ciudad periférica de Lima y en condiciones bastantes precarias. Jeremy, el único sustento familiar, trabajaba de manera informal como la mayoría de venezolanos, vendiendo caramelos de manera ambulante, mientras Kiara, imposibilitada de trabajar por ser menor de edad, se ocupaba del bebé. Pese a reunir esas condiciones, el procedimiento regular impedía que el Estado realizara una evaluación socioeconómica a su caso pues para ello Kiara y su familia debían estar alojados en un albergue reconocido por el Estado.

Hasta marzo 2020, en Lima metropolitana solo había 16 albergues reconocidos por el Estado ${ }^{18}, 14$ de ellos administrados por organizaciones religiosas y los dos restantes por organizaciones privadas (Organización Internacional para las Migraciones 2020b). La gran dificultad es que este tipo de establecimientos, al ser pocos comparado con la cantidad de migrantes, están saturados. La única alternativa para los migrantes en situación de calle es recurrir a los albergues dirigidos por otras organizaciones religiosas o privadas,

17 Según el artículo 29.1 literal C de la Ley de Migraciones - Decreto Legislativo n. 1350 y su Reglamento Decreto Supremo n. 007- 2017-IN

18 El $75 \%$ del total de la población de venezolanos en Perú vive en Lima, según el último informe de ACNUR (2021). 
pero que no son reconocidos por el Estados y que pueden presentar situaciones de hacinamiento u otros peligros. Así, los migrantes venezolanos entran en un sistema donde difícilmente podrán ganar. Entrar en un albergue no reconocido por el Estado bloquea el trámite de la calidad migratoria de residencia humanitaria. No hacerlo implica dormir en la calle y sin comida, esperando que alguna plaza se libere en un albergue del Estado.

Un día antes de que venciera su permiso de estadía y sin opciones a la vista, Jeremy se acercó a la CEPR junto a Kiara y su bebé, los tres presentaron su solicitud de refugio, pero la de Jeremy no fue admitida. Hoy, Kiara y su bebé tienen el carné de solicitante de refugio y, aunque eso les da cierta tranquilidad, en la práctica no hay mucha diferencia. Al ambos ser menores de edad, la situación irregular de Jeremy, el único sustento del hogar, impacta directamente en ellos y los expone a múltiples vulnerabilidades. Incluso si Kiara y su hijo obtuvieran la calidad migratoria de refugiados, en la práctica su situación no cambiaría, seguirían siendo dos NNA dependientes de un adulto en situación irregular y, por lo tanto, irregulares de facto, triplemente vulnerables expuestos a todo tipo de riesgos.

Se observa aquí cómo el interés superior del niño, los tratados internacionales, evocados en la nueva ley de Migraciones entran en conflicto con las prácticas migratorias nacionales y los trámites derivados de éstas. Por ejemplo, la Declaración Americana de los Derechos y Deberes del Hombre en su artículo VIII afirma que «toda mujer en estado de gravidez o en época de lactancia, así como todo niño, tienen derecho a protección, cuidados y ayuda especiales». En el caso de Kiara, se trata de una niña en época de lactancia, además de su bebé, a los que se les niega una debida protección al no observar las particularidades de su caso. Va también en contra de lo expuesto por la Convención de los Derechos del Niño, así como por el Pacto de San José al que Perú también se ha adherido, donde se señala que «el Estado debe asumir una posición especial de garante con mayor cuidado y responsabilidad, y debe tomar medidas especiales orientadas en el principio del interés superior del niño». Observamos que si bien la ley peruana sobre Migraciones y el Plan de Derechos Humanos (MINJUS 2018), reconocen y se comprometen a actuar, en la práctica se homogenizan los casos y se desprotege a los NNA migrantes.

Del mismo modo, la ausencia de respuesta del Estado, el hecho de que la creación y diversificación de dispositivos jurídicos para regular la migración no vayan de la mano con la creación de estructuras de acompañamiento a los migrantes, constituye también 
una posición del Estado frente a la situación migratoria. Una posición que se inscribe en el paradigma utilitarista de la migración, donde los migrantes son aceptados o rechazados en función del beneficio que significan en términos económicos o políticos en determinado contexto, y donde las políticas creadas para regular esta situación son instrumentalizadas hacia ese fin. (Morice 2001). Así, la diversificación de dispositivos migratorios que tienen como resultado final el hacer bascular hacia la irregularidad a la mayoría de migrantes venezolanos, se inscribe en la política de seguridad de fronteras instaurada por el gobierno del entonces presidente del Perú, Martín Vizcarra (20182020).

Retomé contacto con Jeremy y Kiara en abril de 2020, en contexto de emergencia sanitaria por la pandemia de la COVID-19. En los meses previos a la llegada del virus al territorio, Jeremy, en situación irregular, había logrado tejer ciertos vínculos con otros compatriotas $y$, gracias a la venta de caramelos en las calles, lograba alquilar un cuarto en el distrito de Villa El Salvador y sobrevivir con su condición de migrante irregular y su familia a cuestas que, aunque regulares en el papel, seguían siendo irregulares en la práctica al ser dependientes de él por su condición de menores de edad. La primacía de los derechos de ciudadanía frente los derechos humanos son evidentes en este caso. Marginados de la sociedad y con menos oportunidad del resto de ciudadanos, los miembros de la familia de Jeremy son una suerte de sub-ciudadanos o ciudadanos de segunda categoría, cuya existencia civil depende de los nuevos dispositivos del país de acogida.

Debido a las medidas de confinamiento impuestas por el gobierno peruano frente a la pandemia, la situación de esta familia se torna crítica, sin documentos y sin permisos para trabajar, Jeremy y su familia evalúan regresar a Venezuela al igual que otras 55 mil familias que se encuentran en peligro de desalojo (Ojo Público 2020), pues ante la ausencia de trabajo y la obligación del confinamiento no tienen opciones para sobrevivir.

\subsection{NNA en situación irregular con padres en situación regular}

En este otro caso emblemático recibido en la Clínica Jurídica Pedro Arrupe mostraré cómo, producto de la oposición de los marcos normativos descritos, la condición de irregularidad se convierte en la principal amenaza hacia estos NNA, aún cuando sus padres se encuentren en situación regular. Así lo muestra el caso de Zenaida 
Martínez ${ }^{19}$, mujer venezolana con Permiso Temporal de Permanencia y pronta a conseguir una calidad migratoria más estable.

De acuerdo a la legislación actual, después de la expiración del Permiso Temporal de Permanencia, válido por un año, el extranjero venezolano tiene derecho a tramitar de manera automática el carné de Extranjería Especial Residente. Este documento, a diferencia del Permiso Temporal de Permanencia, sí otorga una calidad migratoria y, por lo tanto, permite a la persona que lo detenta acceder a servicios básicos como el Seguro Integral de Salud (MINSA 2015). En Perú, solo el carné de extranjería y la nacionalidad peruana permiten acceder a este derecho de manera gratuita.

Zenaida ingresó al país en el año 2017, cuando estaba vigente el Permiso Temporal de Permanencia y se vivía una política de puertas abiertas liderada por el expresidente peruano Pedro Pablo Kuczynski. Entonces conseguir trabajo era mucho más sencillo y su perfil socioeconómico dista bastante del primer caso. En Venezuela, ella pertenecía a la clase media, había realizado estudios de medicina y trabajaba como asistente de equipos médicos. Su decisión de emigrar estuvo ligada a cuestiones económicas, que no ponían en riesgo su vida, pero sí la dificultaban cada vez más. Cuando ella ingresó a Perú, se instaló en San Miguel, distrito limeño de clase media, donde extrabajadores del sector médico venezolano la esperaban. Estos amigos funcionaron como una red de apoyo económico y moral para ella y para otros venezolanos que se instalaron posteriormente en Perú.

El plan de Zenaida preveía que, una vez instalada en el país y a través de préstamos de esta red de apoyo, pudiera hacer venir a su hijo de seis años y a su madre, y lograr así la reunificación familiar. Sin embargo, en Venezuela no autorizaron la salida de su hijo pues, si bien contaba con la autorización de salida del padre, Zenaida no había tramitado el documento antes de irse. Enviar el documento a través del Consulado venezolano en Perú era casi imposible, tanto por el dinero como por el tiempo extra que el trámite le demandaría. Decidieron entonces que el niño saliera del país de manera irregular, acompañado de su abuela. En esa condición atravesó Colombia y Ecuador. En este último país registraron su ingreso en la base de datos y le entregaron la carta andina como prueba de ello, recuperando así su condición de niño migrante regular. Sin embargo, en esa misma oficina y en

19 Como en el caso anterior, se trata de un nombre ficticio para proteger la identidad de la entrevistada. 
circunstancias que nadie sabe explicar, la partida de nacimiento del niño, apostillada por el Ministerio de Relaciones Exteriores de Venezuela, desapareció. Cuando el hijo de Zenaida llegó al Centro Binacional de Atención Fronteriza, el último paso antes de ingresar a Perú, ante la ausencia de este documento clave las autoridades migratorias lo dejaron entrar pero sin otorgarle ningún documento que probara su ingreso, es decir, entró como irregular.

Actualmente, el hijo de Zenaida asiste a la escuela y está registrado en la base de datos del Ministerio de Educación del Perú a pesar de no tener partida de nacimiento y de que en la base de datos de Migraciones no figure su nombre. Zenaida refiere que por ahora la irregularidad del niño no le ha representado ningún problema práctico, pero ella sabe que, en el futuro, en cuanto cumpla la mayoría de edad, esto le originará varias dificultades.

\section{a. LA IMPOSIBILIDAD DE UN FUTURO PARA LOS NNA MIGRANTES IRREGULARES}

Los problemas a los que se refiere Zenaida ya existen, aunque de manera latente. Hasta ahora, la cierta estabilidad económica de la que goza la familia le ha permitido sortear los primeros inconvenientes. El derecho a acceder a un sistema de salud gratuito es uno de ellos. Al no tener ningún documento de identidad, el hijo de Zenaida no puede acceder al Seguro Integral de Salud (SIS). En las ocasiones en las que ha tenido que atenderse lo ha hecho en una clínica privada, donde el precio de la consulta es de unos 40 euros, comparados con los 2 euros que le costaría atenderse en el SIS. El derecho a la salud, un derecho consustancial al interés superior del niño y reconocido en la legislación nacional e internacional, queda aquí relegado a un plano secundario, poniendo en riesgo su vida. Su situación se agrava si se toma en cuenta que el niño es asmático y que, además, producto de problemas al nacer, tiene cierto retraso cognitivo: su audición es mínima y su capacidad de hablar bastante reducida. Las terapias que podrían ayudarlo le son imposibles de acceder tanto por la vía privada, pues la familia no tiene los recursos para cubrir los 200 euros mensuales que representa en promedio el tratamiento; como por la vía pública, a través del SIS, donde la posibilidad ni siquiera existe al ser un niño sin documentos.

Migraciones, la autoridad correspondiente, declara que no puede hacer nada frente a su caso pues al haber ingresado de manera irregular al país no puede concederle ningún tipo de calidad migratoria. Las autoridades migratorias le han explicado a Zenaida que, dentro de todo, la situación no es tan grave pues su hijo, al ser menor de edad, 
no deberá pagar ninguna multa por el tiempo de permanencia en el país. Sin embargo, al cumplir la mayoría de edad, ese tiempo de gracia llegará a su fin y él estará obligado a abandonar el país y a pagar por el exceso de permanencia.

Sobre el caso de Zenaida Martínez, el equipo legal de la Clínica Jurídica Pedro Arrupe considera que ya que la nueva ley de Migraciones señala que bajo ninguna circunstancia se aplicará sanción alguna contra los NNA (2017, Art. 53.2), debería permitirles regularizar su calidad migratoria en aras de la regularización de su permanencia en el Perú pues, de lo contrario, se estaría hablando de sanciones suspendidas hasta que el niño en cuestión cumpla la mayoría de edad. Asimismo, el equipo jurídico ha asesorado a Zenaida para que presente una solicitud de regularización migratoria del niño ante la Gerencia de Registro Migratorio de Migraciones y para que se registre su ingreso al país, sobre todo teniendo en cuenta que el niño asiste a clases en una entidad estatal y existe información de sobra que permite reconstruir y determinar su ingreso y permanencia en el país. Actualmente, tanto Zenaida como su esposo y padre del niño tienen el carné de extranjería que les permite trabajar y gozar casi de los mismos derechos que un nacional; pese a ello no han logrado que el ingreso de su hijo sea reconocido en Perú.

Hasta la fecha de publicación de este documento, Migraciones no se ha pronunciado al respecto y la solicitud de regularización sigue sin respuesta. Como una manera de hacer presión ante este órgano dependiente del Ministerio del Interior, Zenaida ha recurrido a la Defensoría del Pueblo, un organismo constitucionalmente autónomo cuya función es defender los derechos constitucionales y fundamentales de la persona y de la comunidad, así como supervisar el cumplimiento de los deberes de la administración estatal y la prestación de los servicios públicos a la ciudadanía. Sin embargo, tampoco ha habido una respuesta.

Aunque no consta en ningún documento, en las repetidas ocasiones en las que Zenaida ha acudido a Migraciones para exponer su caso, ella refiere que funcionarios de esta entidad le han aconsejado que la solución más sencilla sería que su hijo saliera de Perú tal como entró, es decir, de manera irregular, con todo el riesgo que una operación de ese tipo implica. El objetivo de esta salida sería conseguir que, acompañado de sus padres, el pasaporte del niño sea sellado tanto en Colombia como en Ecuador y así su ingreso al Perú se inscriba en los registros sin ningún problema. Una alternativa peligrosísima por los riesgos que implica el traslado, pero que se condice con el de varios otros entrevistados en situación similar. 
En el caso del hijo de Zenaida, la contradicción entre los marcos normativos de protección por su minoría de edad, y de exclusión por su calidad de migrante son también evidentes. Si bien la autoridad nacional en materia migratoria le reconoce los derechos propios de un NNA y por ello lo exenta de las multas, al mismo tiempo, ignora su condición de NNA y de dependiente de un adulto para valerse y defender sus derechos en la sociedad, y lo sanciona negándole el derecho a una atención gratuita que podría mejorar su calidad de vida y colocarlo en igualdad de condiciones frente a otros niños nacionales.

Así, el Estado peruano va en contra de tratados internacionales del Sistema interamericano sobre protección de los derechos humanos de NNA migrantes (CIDH 2008) pues todos, "(los) no acompañados, separados, que migraron con sus padres o que nacieron en el país de destino, deben tener acceso irrestricto a los derechos sociales (...) y de modo especial por su vulnerabilidad, los derechos sociales a la educación, la asistencia sanitaria y una vivienda digna, sin importar si son nacionales o extranjeros o migrantes regulares o irregulares». La falta de acceso a una salud de calidad y gratuita atenta directamente contra el interés superior del niño, lo que se verá reflejado en su educación y en posibles situaciones de discriminación como resultado.

\section{Conclusiones}

Uno de los objetivos de este artículo ha sido poner en evidencia el vínculo profundo que existe entre el plano jurídico y el plano sociológico pues, así como «la igualdad en derechos genera el sentido de la igualdad basada en el respeto del otro como igual, la desigualdad de los derechos genera la imagen del otro como desigual, o sea, inferior en el plano antropológico, precisamente por ser inferior en el plano jurídico»(Ferrajoli 2001). Desigualdades que son acentuadas por los actuales dispositivos migratorios y donde la máxima de Walter Benjamin parece cumplirse a cabalidad: desde el punto de vista de los oprimidos, el Estado de excepción es siempre la norma (Durand 2012). Esto hace que, en la práctica, la discriminación y el desprecio cultural otorguen la cobertura necesaria para negar al extranjero derechos sociales de tipo distributivo, llámese acceso a atención médica gratuita, planes de apoyo o terminen por fragilizar el acceso a la educación.

La falta de acceso a un derecho desencadena consecuencias negativas que trastocan a toda una familia, incluyendo el recorte de 
derechos fundamentales para niños como es el caso de Kiara y su bebé. Desde el inicio, la condición de la nacionalidad se impone como la principal diferencia entre unos y otros. Si a lo largo de la historia, los derechos eran otorgados o restringidos en función de sexo, instrucción o nacimiento, hoy el nuevo paradigma parece estar marcado por el status de ciudadano y de su nacionalidad; es el migrante de hoy quien ve limitados sus derechos a través de una discriminación jurídica y de los dispositivos de excepción que aplican sobre él.

El ejercicio de documentación de los casos de Kiara Peña y de Zenaida Martínez ilustra las situaciones de vulnerabilidad que enfrentan los NNA migrantes en el actual contexto peruano, donde si bien existen diferencias de acuerdo al estrato social al que pertenecen cada uno de los casos, al final ambos se encuentran sometidos a la aplicación del mismo marco normativo que influirá en el presente y en las posibilidades de desarrollo a futuro de estos NNA migrantes. Frente a la irregularidad migratoria de los NNA o de sus representantes, las respuestas de las autoridades correspondientes han sido homogéneas como si todos los casos fueran iguales, con lo cual se invisibiliza las complejidades, particularidades y vulnerabilidades de cada caso. Se observa además que pese a los compromisos internacionales adquiridos por el Estado peruano y establecidos en el DL 1350 así como en la ley $30466^{20}$, Migraciones no aplica el interés superior del niño. Por el contrario, se evidencia que las decisiones tomadas van en contra del mismo, y podrían significar la responsabilidad internacional del Estado peruano respecto de sus obligaciones derivadas del Derecho Internacional de los Derechos Humanos.

Para los NNA migrantes, la irregularidad se presenta como el principal riesgo y como una tercera vulnerabilidad que se suma la de su condición de no nacionales y de personas limitadas para ejercer sus derechos en tanto necesitan de un adulto o tutor que los represente (PICUM 2013, 13). Así, los enemigos de la migración no solo son las grandes mafias de traficantes acusadas por los gobernantes, lo es también el fomento de la migración irregular a través de dispositivos de excepción que terminan castigando a personas vulnerables y a los hijos de estos.

20 La ley 30466, ley que establece parámetros y garantías procesales para la consideración primordial del interés superior del niño y su reglamento, el Decreto Supremo No 002-2018-MIMP. 


\section{Bibliografía}

ACNUR. 2019. Las tendencias globales de desplazamiento forzado 2019. Acceso el 21 de enero de 2021. https://www.acnur.org/5eeaf5664.pdf.

ACNUR. 2020. Manual para la orientación legal a personas solicitantes de la condición de refugiado, refugiadas y migrantes en Perú. Acceso el 17 de febrero 2021. https://data2.unhcr.org/en/documents/details/84243

ACNUR. 2021. Regional refugee and migrant response plan January December 2021. Acceso el 20 de febrero 2021. https://rmrp.r4v.info

Acosta, Diego, Cécile Blouin y Luisa Freier. 2019. «La emigración venezolana: respuestas latinoamericanas», Fundación Carolina 2, n. 3: 1-30. https:// doi.org/10.13140/RG.2.2.33921.71523.

Blouin, Cécile, Isabel Berganza y Luisa Feline Freier. 2018. "The spirit of Cartagena? Applying the extended refugee definition to Venezuelans in Latin America». Forced Migration Review 63: 64-66. Acceso el 18 de agosto 2020. https://www.fmreview.org/cities/blouin-berganza-freier.

Cabo, Antonio de, y Gerardo Pisarello. 2017. "¿La ciudad está tranquila? Inmigración y derechos en la crisis de la 'mundialización feliz'», Revista de La Facultad de Derecho de México 57, n. 248: 11-40. Acceso el 18 de agosto 2020. https://doi.org/10.22201/fder.24488933e.2007.248.61496.

Ceriani, Pablo. 2018. Migration policies and human rights in Latin America: Progressive practices, old challenges, worrying setbacks, and new threats. Acceso el 18 de agosto 2020. https://repository.gchumanrights. org/bitstream/handle/20.500.11825/629/PolicyBrie f_LatinAmerica_ ok. pdf? sequence $=4 \&$ isAllowed $=\mathrm{y}$.

$\mathrm{CIDH}$. 2008. La infancia y sus derechos en el Sistema Interamericano de Protección de Derechos Humanos. Acceso el 17 de abril 2020. https://cidh. oas.org/countryrep/Infancia2sp/Infancia2cap1.sp.htm.

Clínica Jurídica de los derechos de las personas migrantes y refugiadas, IDEHPUCP. 2020. Guía sobre la protección de los derechos de las personas migrantes, refugiadas y apátridas en el Perú. Acceso el 21 de enero 2021. https://facultad. pucp.edu.pe/derecho/wp-content/uploads/2020/08/ Guía-Protección-de-los-Derechos-de-las-Personas-Migrantes-Refugiadas-yApátridas-en-el-Perú.pdf.

Coordinadora Nacional de Derechos Humanos Perú. 2020. Informe alternativo al Comite de Proteccion de los Derechos de todos los trabajadores migratorios y de sus familiares - Perú. Lima: Coordinadora Nacional de Derechos Humanos.

Corte Interamericana de Derechos Humanos. 2002. Opinión Consultiva n. 17. Condición Jurídica y Derechos Humanos Del Niño, 88.

Durand, Manuel V. 2012. Estado de excepción permanente. Conceptos y fenómenos fundamentales de nuestro tiempo. México D.F.: Universidad Nacional Autónoma de México Instituto de Investigaciones Sociales.

Ferrajoli, Luigi. 2001. "Los fundamentos de los derechos fundamentales». En Derechos Fundamentales, editado por Antonio de Cabo y Gerardo Pisarelo, 19-56. Madrid: Trotta 
Instrumentos Regionales sobre Refugiados y temas relacionados (1984). Declaración de Cartagena sobre Refugiados, Adoptado por el «Coloquio Sobre la Protección Internacional de los Refugiados en América Central, México y Panamá: Problemas Jurídicos y Humanitarios», 22 Noviembre. Acceso el 29 de enero 2021. https://www.refworld.org.es/ docid/50ac93722.html

Koechlin, José, Eduardo Vega y Ximena Solórzano. 2018. «Migración venezolana al Perú: proyectos migratorios y respuesta del Estado». En El éxodo venezolano: Entre el exilio y la emigración, editado por J. Koechlin y J. Eguren, 47-96. Lima: UARM, KAS, OIM y OBIMID. Acceso el 29 de enero 2021. https://www.uarm.edu.pe/FondoEditorial/etica-desarrollo/el-exodovenezolano-entre-exilio-emigracion\#.YJABdy_pNpS

Marshall, Thomas H. 1997. "Ciudadanía y clase social», Reis 79: 297-344. Acceso el 13 de junio 2020. http://www.jstor.org/discover/10.2307/4018 4017 ? uid $=3737784 \&$ uid $=2134 \&$ uid $=2 \&$ uid $=70 \&$ uid $=4 \&$ sid $=2110475447$ 6317.

Ministerio del Interior. 2017. «Reglamento del Decreto Legislativo n. 1350», Diario Oficial El Peruano n. 1402: 51-75. Acceso el10 de diciembre 2020. http://www.minam.gob.pe/wp-content/uploads/2017/12/ds_014-2017minam.pdf.

MINJUS. 2018. Plan Nacional de Derechos Humanos de Perú 2018-2021. Acceso el 18 de enero 2021 http://spij.minjus.gob.pe/content/banner_ secundario/img/muestra/PLAN-ANUAL.pdf

MINSA. 2015. "Directiva administrativa que regula el proceso de afiliación al régimen de financimaiento subsidiado del seguro integral de salud». Diario Oficial El Peruano, n. 15643: 24-25. Acceso el 5 de noviembre 2019. https://busquedas.elperuano.pe/normaslegales/aprueban-directivaadministrativa-que-regula-los-procedimien-resolucion-jefatural-no-1122020sis-1886225-1/

Morice, Alain. 2001. "'Choisis, contrôlés, placés' - Renouveau de l'utilitarisme migratoire», Vacarme 14: 56-60.

Morice, Alain. 2015. "Situation actuelle des migrations internationales: Réalités et controverses», L'information Psychiatrique 91, n. 3: 207-215. https:// doi.org/10.3917/inpsy.9103.0207.

Omar Lucas y Elizabeth Salazar. 2020. «El doble éxodo: La pandemia fuerza el retorno de venezolanos al país que dejaron». Ojo Publico, 24 de junio. Acceso el 5 de diciembre 2020. https://ojo-publico.com/1919/el-dobleexodo-la-pandemia-fuerza-el-retorno-de-venezolanos.

Organización de las Naciones Unidas. 2005. «Observación General n. 5. Tratado de los menores no acompañados y separados de su familia fuera de su país de origen», vol. 6. Acceso el 17 de enero 2021. https://www. acnur.org/fileadmin/Documentos/BDL/2005/3886. pdf?file=fileadmin/ Documentos/BDL/2005/3886.

Organización Internacional para las Migraciones. 2020a. "Monitoreo de flujo de población venezolana en El Perú DTM. Ronda 7», 1-17. Acceso el 5 de 
noviembre 2020. https://www.unicef.org/peru/media/6361/file/DTM 7 Datos sobre población venezolana en Perú.pdf.

Organización Internacional para las Migraciones (OIM). 2020b. «Evaluación de sitios albergues para población venezonala en Lima Metropolitana Reporte $1 »$. Acceso el 5 de abril 2020. https://reliefweb.int/report/peru/ dtm-evaluaci-n-de-sitios-albergues-para-poblaci-n-venezolana-en-limametropolitana

PICUM. 2013. Niños primero y ante todo. Bruselas: Plataforma para la Cooperación Internacional sobre Inmigrantes Indocumentados.

Presidencia de Colombia. n.d. Estado colombiano concede la nacionalidad a niños nacidos en Colombia, hijos de migrantes venezolanos, para proteger sus derechos. Acceso el 13 de noviembre de 2019. https://id.presidencia. gov.co/Paginas/prensa/2019/190805-Estado-colombiano-nacionalidadninos-nacidos-Colombia-hijos-migrantes-venezolanos-proteger-susderechos.aspx.

Sayad, Abdelmalek. 2006. L'immigration ou les paradoxes de l'altérité. 2. Les enfants illégitimes. Paris: Raisons d' Agir.

Senovilla, Daniel. 2014. "Analyse d' une catégorie juridique récente: Le mineur étranger non accompagné, séparé ou isolé» 30.

Villarreal, Karina (2020). «El nuevo precio del pasaporte supera los 14 millones de bolivares», El Espectador, 15 de enero. Acceso el 15 de diciembre 2020. https://www.elnacional.com/economia/el-nuevo-precio-del-pasaportesupera-los-14-millones-de-bolivares/ 


\section{Anexo 1: Evoluciones de las principales normativas y prácticas migratorias en Perú}

\begin{tabular}{|c|c|c|c|c|}
\hline $\begin{array}{c}\text { Normativas/ } \\
\text { Prácticas }\end{array}$ & Definición & Normativa & Condiciones & Plazos \\
\hline \multirow[t]{4}{*}{$\begin{array}{l}\text { PTP - Permiso } \\
\text { Temporal de } \\
\text { Permanencia }\end{array}$} & $\begin{array}{l}\text { Documento creado } \\
\text { exclusivamente para } \\
\text { los venezolanos. } \\
\text { No es una calidad } \\
\text { migratoria. } \\
\text { Permite residir y } \\
\text { trabajar. }\end{array}$ & $\begin{array}{l}\text { Decreto Supremo } \\
\text { n. 002-2017-IN, } \\
\text { publicado el } 3 \text { de } \\
\text { enero de } 2017\end{array}$ & \multirow{4}{*}{$\begin{array}{l}\text { - Ingreso regular } \\
\text { - Condición } \\
\text { regular o } \\
\text { irregular por } \\
\text { vencimiento } \\
\text { de permiso de } \\
\text { permanencia } \\
\text { - No tener } \\
\text { antecedentes } \\
\text { penales, } \\
\text { policiales ni } \\
\text { judiciales. }\end{array}$} & $\begin{array}{l}\text { Para personas que } \\
\text { ingresaron antes de } \\
2 / 02 / 2017 \text {. Plazo } \\
\text { de } 120 \text { días hábiles } \\
\text { para presentar } \\
\text { solicitud }\end{array}$ \\
\hline & & $\begin{array}{l}\text { Decreto Supremo } \\
\text { n. 023-2017- IN, } \\
\text { publicado el } 29 \text { de } \\
\text { julio de } 2017\end{array}$ & & $\begin{array}{l}\text { Válido para los que } \\
\text { ingresaron hasta el } \\
31 / 07 / 2017 \text {. Plazo } \\
\text { de } 120 \text { días para } \\
\text { presentar solicitud. }\end{array}$ \\
\hline & & $\begin{array}{l}\text { Decreto Supremo } \\
\text { n. } 001-2018-\text { IN, } \\
\text { publicado el } 23 \text { de } \\
\text { enero de } 2018 .\end{array}$ & & $\begin{array}{l}\text { Válido para personas } \\
\text { que ingresaron antes } \\
\text { del 31/12/2018. } \\
\text { Tramitarlo hasta } \\
\text { 30/06/2019. }\end{array}$ \\
\hline & & $\begin{array}{l}\text { Decreto Supremo } \\
\text { n. 007-2018- IN, } \\
\text { publicado el } 19 \text { de } \\
\text { agosto de } 2018\end{array}$ & & $\begin{array}{l}\text { Reducción de plazos } \\
\text { para el ingreso } \\
\text { al país: hasta el } \\
31 / 10 / 2018 \text {; y para } \\
\text { presentar la solicitud } \\
\text { hasta el } 31 / 12 / 2018\end{array}$ \\
\hline $\begin{array}{l}\text { Obligatoriedad } \\
\text { del pasaporte }\end{array}$ & $\begin{array}{l}\text { Requisito } \\
\text { obligatorio para } \\
\text { ingresar al Perú } \\
\text { para personas } \\
\text { venezolanas. }\end{array}$ & $\begin{array}{l}\text { Resolución de } \\
\text { Superintendencia } \\
\text { Nacional de } \\
\text { Migraciones n. } \\
\text { 000270-2018- } \\
\text { MIGRACIONES del } \\
24 \text { de agosto de } \\
2018\end{array}$ & $\begin{array}{l}\text { Tramitarlo en } \\
\text { Venezuela. }\end{array}$ & $\begin{array}{l}\text { A partir del } \\
\text { 25/08/2018. } \\
\text { El 5/10/2018, gracias } \\
\text { a un hábeas corpus } \\
\text { se deja sin efecto. } \\
\text { En enero de } 2019 \\
\text { entra nuevamente } \\
\text { en vigencia. }\end{array}$ \\
\hline $\begin{array}{l}\text { Visa humanitaria } \\
\text { en Perú }\end{array}$ & $\begin{array}{l}\text { Requisito para } \\
\text { ingresar al Perú } \\
\text { para personas } \\
\text { venezolanas. } \\
\text { Excepciones: } \\
\text { NNA, mujeres } \\
\text { embarazadas, } \\
\text { mayores de } 65 \text { años } \\
\text { con enfermedad } \\
\text { grave. }\end{array}$ & $\begin{array}{l}\text { Resolución de la } \\
\text { Superintendencia } \\
\text { Nacional de } \\
\text { Migraciones } n \text {. } \\
000177-2019 \text { del } \\
12 \text { de junio del } \\
2019 \text {. }\end{array}$ & $\begin{array}{l}\text { Tramitarla en } \\
\text { los Consulados } \\
\text { de Perú en } \\
\text { Venezuela, } \\
\text { Colombia o } \\
\text { Ecuador. } \\
\text { Contar con } \\
\text { pasaporte vigente } \\
\text { No presentar } \\
\text { antecedentes. }\end{array}$ & $\begin{array}{l}\text { Entra en vigor } \\
\text { a partir del } \\
15 / 06 / 2019 .\end{array}$ \\
\hline
\end{tabular}




\begin{tabular}{|c|c|c|c|c|}
\hline $\begin{array}{l}\text { Normativas/ } \\
\text { Prácticas }\end{array}$ & Definición & Normativa & Condiciones & Plazos \\
\hline $\begin{array}{l}\text { Evaluación } \\
\text { acelerada en } \\
\text { frontera para } \\
\text { solicitar el } \\
\text { refugio }\end{array}$ & $\begin{array}{l}\text { Sistema de } \\
\text { Protección del } \\
\text { Refugiado cambió } \\
\text { en las prácticas } \\
\text { para solicitar el } \\
\text { refugio. Prohibición } \\
\text { de ingreso al país. }\end{array}$ & & $\begin{array}{l}\text { Esperar en la } \\
\text { frontera mientras } \\
\text { presentan la } \\
\text { solicitud y realizan } \\
\text { la entrevista. } \\
\text { Duración: meses }\end{array}$ & $\begin{array}{l}\text { A partir del } \\
22 / 06 / 2019\end{array}$ \\
\hline $\begin{array}{l}\text { Visa humanitaria } \\
\text { en Ecuador }\end{array}$ & $\begin{array}{l}\text { Anula, en la } \\
\text { práctica, «las } \\
\text { excepciones } \\
\text { humanitarias» para } \\
\text { los mayores de } 65 \\
\text { años, NNA, mujeres } \\
\text { embarazadas, en la } \\
\text { frontera peruana. }\end{array}$ & $\begin{array}{l}\text { Resolución } \\
\text { Administrativa } \\
\text { n. } 0000101 \text { del } \\
26 \text { de agosto de } \\
2019 .\end{array}$ & $\begin{array}{l}\text { Necesaria para } \\
\text { ingresar a } \\
\text { Ecuador. } \\
\text { Tramitarla en } \\
\text { Caracas, Bogotá } \\
\text { o Lima. } \\
\text { Costo } \$ 50 .\end{array}$ & $\begin{array}{l}\text { Desde el } \\
\text { 26/08/2019. } \\
\text { A partir de } \\
\text { esa fecha, los } \\
\text { funcionarios } \\
\text { peruanos exigen } \\
\text { el sello de salida } \\
\text { de Ecuador en } \\
\text { el pasaporte } \\
\text { para permitir el } \\
\text { ingreso incluso de } \\
\text { personas con visa } \\
\text { humanitaria. }\end{array}$ \\
\hline $\begin{array}{l}\text { Expulsiones } \\
\text { colectivas } \\
\text { express: } \\
\text { «Plan Migración } \\
\text { Segura 2019» y } \\
\text { «Plan Migrantes } \\
\text { Ilegales 2019» }\end{array}$ & $\begin{array}{l}\text { Operativos } \\
\text { coordinados para } \\
\text { expulsar a personas } \\
\text { venezolanas, } \\
\text { incluidas las } \\
\text { solicitantes de } \\
\text { refugio, padres } \\
\text { de NNA peruanos } \\
\text { y padres de } \\
\text { NNA migrantes } \\
\text { venezolanos. }\end{array}$ & $\begin{array}{l}\text { Plan de } \\
\text { Operaciones } \\
\text { n. 021-2019- } \\
\text { DIRNOS-PNP/ } \\
\text { DIRSEEST-UNIPLA. }\end{array}$ & $\begin{array}{l}\text { Personas con } \\
\text { antecedentes } \\
\text { penales o } \\
\text { policiales o } \\
\text { que habrían } \\
\text { presentado } \\
\text { documentación } \\
\text { falsa. }\end{array}$ & $\begin{array}{l}\text { Desde abril de } 2019 . \\
\text { Desde la } \\
\text { detención hasta la } \\
\text { deportación, entre } \\
12^{\star} \text { y } 24 \text { horas, } \\
\text { según testimonios } \\
\text { recogidos durante } \\
\text { el trabajo de campo } \\
\text { de setiembre a } \\
\text { diciembre } 2019 \text { en } \\
\text { Perú. }\end{array}$ \\
\hline $\begin{array}{l}\text { CPP - Carné } \\
\text { de Permiso } \\
\text { Temporal de } \\
\text { Permanencia }\end{array}$ & $\begin{array}{l}\text { Documento } \\
\text { entregado después } \\
\text { de haber obtenido } \\
\text { el Permiso Temporal } \\
\text { de Permanencia. } \\
\text { Dirigido a todas } \\
\text { las personas } \\
\text { extranjeras en el } \\
\text { país. }\end{array}$ & $\begin{array}{l}\text { Decreto Supremo } \\
\text { n. } 010-2020-I N, \\
\text { publicado el } 21 \\
\text { octubre de } 2020 \text {. }\end{array}$ & \begin{tabular}{|l|} 
Estar en situación \\
irregular por \\
vencimiento de \\
documentos o por \\
ingreso irregular. \\
No poseer \\
antecedentes \\
penales, policiales \\
o judiciales.
\end{tabular} & $\begin{array}{l}\text { Válido para los que } \\
\text { ingresaron al Perú } \\
\text { hasta el 20/10/2020. }\end{array}$ \\
\hline
\end{tabular}

Fuente: Elaboración propia en base a las resoluciones citadas 


\section{Copyright}

Deusto Journal of Human Rights / Revista Deusto de Derechos Humanos is an Open Access journal; which means that it is free for full and immediate access, reading, search, download, distribution, and reuse in any medium only for non-commercial purposes and in accordance with any applicable copyright legislation, without prior permission from the copyright holder (University of Deusto) or the author; provided the original work and publication source are properly cited (Issue number, year, pages and DOI if applicable) and any changes to the original are clearly indicated. Any other use of its content in any medium or format, now known or developed in the future, requires prior written permission of the copyright holder.

\section{Derechos de autoría}

Deusto Journal of Human Rights / Revista Deusto de Derechos Humanos es una revista de Acceso Abierto; lo que significa que es de libre acceso en su integridad inmediatamente después de la publicación de cada número. Se permite su lectura, la búsqueda, descarga, distribución y reutilización en cualquier tipo de soporte sólo para fines no comerciales y según lo previsto por la ley; sin la previa autorización de la Editorial (Universidad de Deusto) o la persona autora, siempre que la obra original sea debidamente citada (número, año, páginas y DOI si procede) y cualquier cambio en el original esté claramente indicado. Cualquier otro uso de su contenido en cualquier medio o formato, ahora conocido o desarrollado en el futuro, requiere el permiso previo por escrito de la persona titular de los derechos de autoría. 